Article

\title{
Sulfate Radicals-Based Technology as a Promising Strategy for Wastewater
}

\author{
María Arellano, Marta Pazos $@$ and María Ángeles Sanromán * \\ BIOSUV Research Group, Centro de Investigación Tecnolóxico Industrial-MTI, University of Vigo, Campus As \\ Lagoas-Marcosende, 36310 Vigo, Spain \\ * Correspondence: sanroman@uvigo.es; Tel.: +34-986-812-383
}

Received: 10 July 2019; Accepted: 13 August 2019; Published: 15 August 2019

\begin{abstract}
This study was focused on the generation of sulfate radicals and their applicability as powerful oxidants for degrading complex organic compounds with the final objective of operating in flow systems. To this end, the removal of two compounds from the pharmaceutical industry was assessed, lissamine green and prednisolone. Initially, sulfate radicals were generated by the activation of persulfate with iron as homogenous catalyst, and the key parameters involved in the process, as catalyst concentration and oxidant dosage, were evaluated. Furthermore, with the aim of preventing the secondary contamination due to metal leaching and to be operate in a continuous mode, a heterogeneous catalyst was developed. For it, the iron was fixed on a cationic resin as Amberlite IR120 Na+ form. It was demonstrated that the removal of both pollutants increases with greater catalyst dosages, achieving a decay of $85 \%$ within 25 min with $30 \mathrm{~g} \cdot \mathrm{L}^{-1}$ of catalyst. Moreover, the reuse capability of the catalyst was tested, illustrating that it is rough enough for its reuse. Conversely, in order to develop a continuous treatment in flow system, a fixed bed reactor was constructed and its feasibility was proven. Different experiments with residence times from $10 \mathrm{~min}$ to 60 min were performed, obtaining a removal level of $\approx 95 \%$ and $90 \%$ for prednisolone and lissamine green, respectively, at residence time of $60 \mathrm{~min}$. In conclusion, the potential of sulfate radicals-based technology for degrading organic contaminants has been demonstrated.
\end{abstract}

Keywords: sulfate radicals; prednisolone; lissamine green; heterogeneous catalysis; flow system

\section{Introduction}

Over the last decades, the development of industrial technologies, agricultural activities, population growth, and urban development have promoted the continuous release of organic compounds that have been classified as potential threat to the aquatic ecosystems and human health. Among the existing contaminants, emerging pollutants such as pharmaceutical products have been detected at low concentrations in wastewater treatment plants and they are becoming an increasing concern. Among them, the consumption of pharmaceutical products like lissamine green or prednisolone has been raising. This fact is due to the fact that lissamine green is used as vital stain, which stains membrane degenerate cells, dead cells, and mucus [1], since it is much better tolerated than the premier dye for conjunctival staining Rose Bengal. In addition, due its anthraquinonic chromophore group and its wide use, this dye is considered as a harmful and recalcitrant contaminant. It has been used as a model pollutant in several studies [2-4]. Prednisolone is a steroid medication used in humans and veterinary to treat determined kinds of allergies, inflammatory conditions, cancers, and autoimmune disorders [5]. In the last years, the prednisolone consume is growing, being metabolically stable in the body and discharged rapidly via urine with uncharged forms or metabolite products. Consequently, prednisolone is ubiquitous in rivers and lakes detected at low concentration of ng. $\mathrm{L}^{-1}$ or $\mu \mathrm{g} \cdot \mathrm{L}^{-1}$. In the literature, several studies reported the detrimental effects of prednisolone on various 
of non-target aquatic organisms [6,7]. Among them, it has been demonstrated that this pharmaceutical compound altered the mineral content, increasing the matrix breakdown, that induces an osteoporotic phenotype in regenerating scales of zebrafish [8]. Bal et al. [6,9] reported the effect of prednisolone at low concentrations ranges (lower than $125 \mu \mathrm{g} \cdot \mathrm{L}^{-1}$ ) in the egg masses of Physa acuta, which has a negative effect on growth, heart rate, and survival, as well as remarkable deformities in embryonic growth. Furthermore, the continual exposure of prednisolone at low concentrations $\left(10 \mu \mathrm{g} \cdot \mathrm{L}^{-1}\right)$ alters several parameters, such as average time to first progeny, body length, or mean progeny size, and it is visually detected at early life stages of zebrafish (Danio rerio).

Nowadays, water quality is essential to human health, social and economic development, and the ecosystem. However, due to the global water scarcity, there is an absolute necessity to increase the wastewater reuse for human consumption. Thus, greater purity standards have to be reached to remove all these contaminants as pharmaceutical products, making possible a safe use of treated water [10]. For this reason, the wastewater must be carefully managed to achieve these standard levels. In this vein, a constant search for new wastewater treatment and technologies, more efficient and respectful with the environment, is required [11].

In recent years, a great effort has been made to develop more friendly strategies to overcome this environment problem [12-14]. Advanced Oxidation Processes (AOPs) are known to be powerful procedures for the elimination of complex organic contaminants that the traditional processes are not capable to remove. These methods are based on the in situ production of mighty oxidants, such as hydroxyl radicals $\left(\mathrm{HO}^{\bullet}\right)$, which attack the pollutants until their mineralization [15]. Lately, sulfate radicals-based technology has drawn the attention of scientific community [16,17]. This is because the sulfate radicals $\left(\mathrm{SO}_{4}{ }^{--}\right)$, at neutral $\mathrm{pH}$, show a reduction potential $(2.5-3.1 \mathrm{~V})$ higher than hydroxyl radicals $(1.8-2.7 \mathrm{~V})$, being more selective for oxidation. Likewise, they have a larger $\mathrm{pH}$ range (2.0-8.0) and considerably longer half-life period [18]. Sulfate radicals can be produced through activation of persulfate $\left(\mathrm{S}_{2} \mathrm{O}_{8}{ }^{2-} ; \mathrm{PS}\right)$ or peroxymonosulfate $\left(\mathrm{HSO}_{5}{ }^{-} ; \mathrm{PMS}\right)$. Up to date, it has been reported in literature that several systems are able to produce the activation of these species, such as the presence of transition metals, conduction electron, UV irradiation, ultrasound, and so on $[19,20]$. Figure 1 shows some of these processes.

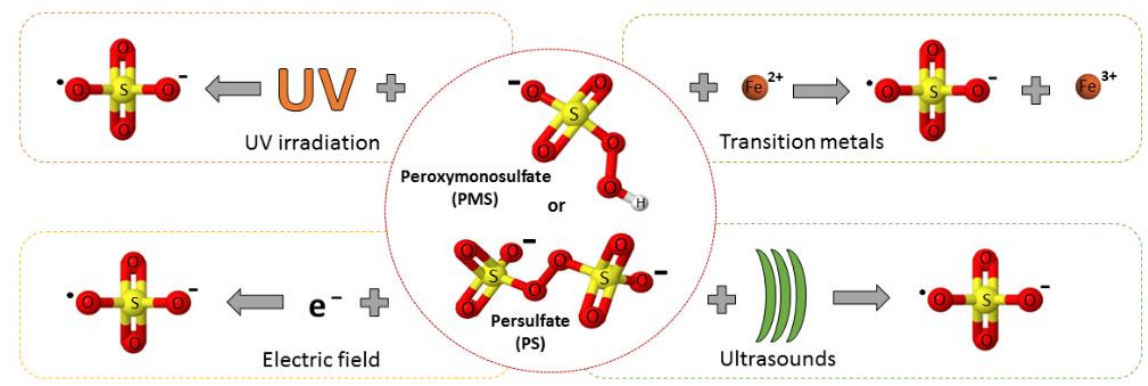

Figure 1. Different activation methods of persulfate and peroxymonosulfate in order to generate sulfate radicals.

Among all them, the addition of transition metal ions such as iron seems to be one of the best options to generate sulfate radicals [21]. Overall reactions involved in the generation of sulfate radicals from persulfate using iron-based catalyst are described by the following equations (Equations (1) and (2)) [22]:

$$
\begin{gathered}
\mathrm{S}_{2} \mathrm{O}_{8}^{2-}+\mathrm{Fe}^{2+} \rightarrow \mathrm{Fe}^{3+}+\mathrm{SO}_{4}^{2-}+\mathrm{SO}_{4}^{-\bullet} \\
\mathrm{SO}_{4}^{-\bullet}+\mathrm{Fe}^{2+} \rightarrow \mathrm{Fe}^{3+}+\mathrm{SO}_{4}^{2-}
\end{gathered}
$$

The main limitation of this technology is the presence of metal ions in the effluents during and after the treatment. As is mentioned by Zhang et al. [23], homogeneous transition metals catalysis or natural minerals containing iron (such as pyrite, goethite, magnetite) [24] not only cause pollution, but require 
high energy or chemical inputs and high operating costs. For this reason, potential future directions of the heterogeneous catalyst/PS or PMS system are proposed to further improve the understanding and sustainability of the system. However, this heterogeneous catalysis can cause secondary contamination due to metal leaching and is plagued by recovery problems. Recently, some researches have attempted to fixed iron on porous materials using no complex fabrication procedures. In this case, the catalyst must be easy scale-up, increasing the activity and stability of the iron along the treatment with the possibility to operate in flow systems [25-27].

Up to now, due the detrimental effects of both pollutants, several degradation processes were performed to remove lissamine green and prednisolone in aqueous environments [28,29]. However, to our knowledge, the sulfate radical generated from persulfate has never been attempted in degradation processes by operation at bench scale and continuous mode.

In this context, the objectives of this study were the following: (i) to evaluate the potential use of persulfate as active oxidant in the treatment of pharmaceutical products as lissamine green and prednisolone, (ii) to synthetize a heterogeneous catalyst by immobilization of iron on a resin as amberlite, (iii) to determine the applicability of persulfate activation process by heterogeneous catalyst to the treatment of these contaminants at larger scale and (iv) to develop a flow treatment system capable to operate with high stability in continuous mode.

\section{Materials and Methods}

\subsection{Chemicals}

The target pollutants of this work were lissamine green and prednisolone (Sigma Aldrich, Madrid, Spain) (Figure 2). Persulfate $\left(\mathrm{Na}_{2} \mathrm{~S}_{2} \mathrm{O}_{8}\right)$ and iron (II) sulfate heptahydrate $\left(\mathrm{FeSO}_{4} \cdot 7 \mathrm{H}_{2} \mathrm{O}\right)$ were acquired from Sigma Aldrich in analytical grade. All reagents were employed without additional purification. Solutions were made employing purified water obtained from an AquaMax-Basic equipment.

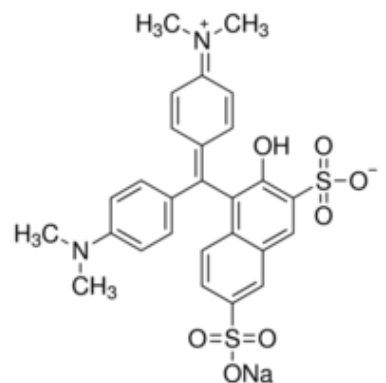

(A)

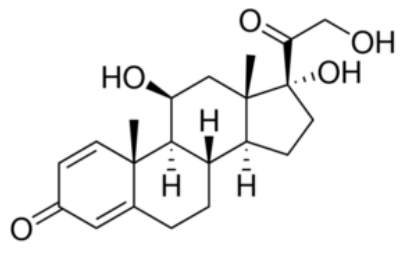

(B)

Figure 2. Chemical structure of (A) lissamine green and (B) prednisolone.

\subsection{Homogeneous Catalysis Experiments}

On the one hand, the homogeneous degradation of lissamine green was evaluated through the activation of persulfate at different iron levels $(0-0.3 \mathrm{mM})$. These trials were performed in a cylindrical glass reactor of $0.25 \mathrm{~L}$ with $0.10 \mathrm{~L}$ of lissamine green solution $\left(7.5 \mathrm{mg} \cdot \mathrm{L}^{-1}\right)$ [30,31] and persulfate concentration was $1 \mathrm{mM}$. In order to analyze the dye concentration and $\mathrm{pH}$, samples $(0.5 \mathrm{~mL})$ were taken regularly and were mixed with $20 \%$ methanol to stop the reaction. All the trials were carried out in duplicate, the averages were presented in the figures, and the standard deviation was below $5 \%$.

\subsection{Heterogeneous Catalysis Experiments}

These trials were performed similarly to prior tests, in a cylindrical glass reactor of $0.25 \mathrm{~L}$ with a solution of lissamine green $\left(7.5 \mathrm{mg} \cdot \mathrm{L}^{-1}\right)$ or prednisolone $\left(25 \mathrm{mg} \cdot \mathrm{L}^{-1}\right)$. The experiments were assessed in duplicate with standard deviations below $5 \%$. The catalyst concentration was optimised and the persulfate concentration was $1 \mathrm{mM}$. Based on the optimal conditions determined at flask scale, the 
system was scaled-up at bench-scale. For that purpose, a mechanically stirred tank was employed, operating with a 2-L Biostat B Braun (1.5 L working volume) using an impeller dual Rushton-type and equipped with a control unit.

\subsubsection{Preparation of Heterogeneous Catalyst}

The heterogeneous catalyst was made by fixing the iron by ion exchange on a cationic resin as Amberlite IR $120 \mathrm{Na}^{+}$form. The manufacturing process was performed by mingling $10 \mathrm{~g}$ of amberlite with a $0.36 \mathrm{M} \mathrm{FeSO}_{4} \cdot 7 \mathrm{H}_{2} \mathrm{O}$ solution. They were left in contact during $24 \mathrm{~h}$, washing with distilled water and after that, heated in an oven at $50{ }^{\circ} \mathrm{C}$ to eliminate the moisture.

\subsubsection{Catalyst Characterization}

In order to realize the characterization of synthesized catalyst, a Scanning Electron Microscopy and Energy Dispersive Spectrometry JEOL JSM-6700F (SEM/EDS) were used to obtain the elemental composition and its distribution on the catalyst. The SEM is equipped with an EDS Oxford Inca Energy 300 SEM using an accelerating voltage of $20 \mathrm{kV}$. These analyses were done in the CACTI Electron Microscopy Service from University of Vigo.

\subsubsection{Catalyst Reuse}

The reuse of the catalyst was assessed by comparing the lissamine green profiles in 5 repeated reaction series where the catalyst was collected and recycled. To this end, after each series, the catalyst was recovered by filtration using a vacuum system. Next, it was submerged in distilled water and, after separation, dried at $50{ }^{\circ} \mathrm{C}$. The recycled catalyst was added into a new lissamine green solution. A new reaction experiment started by mixing all the components with equal concentration of persulfate under magnetic stirring, and the lissamine green removal was following along the reaction time. The assays were performed in duplicate with a standard deviation less than $5 \%$.

\subsubsection{Flow System Using a Fixed Bed Reactor}

The performance tests operating in a flow system were carried out in a fixed bed reactor. The schematic diagram of the experimental system is shown in Figure 3. For this study, the efficiency of the treatment was evaluated at several residence times, from $10 \mathrm{~min}$ to $60 \mathrm{~min}$, using a solution of prednisolone $\left(25 \mathrm{mg} \cdot \mathrm{L}^{-1}\right)$ and lissamine green $\left(7.5 \mathrm{mg} \cdot \mathrm{L}^{-1}\right)$. These experiments were conducted in duplicate, the averages were presented in the figures, and the standard deviation was below $5 \%$.

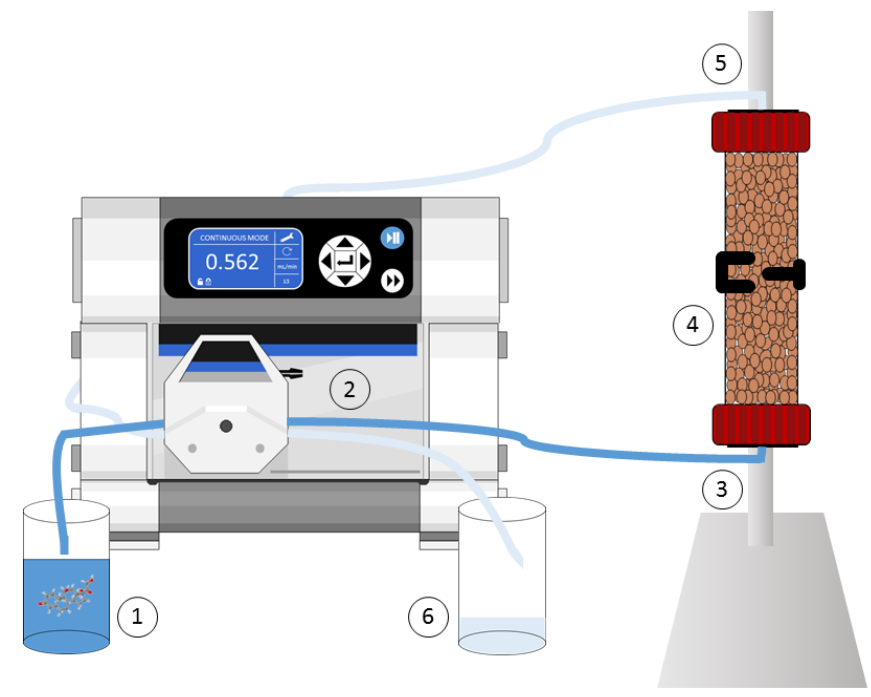

Figure 3. Schematic diagram of the flow system: (1) contaminated initial solution, (2) peristaltic pump, (3) input of the column, (4) column, (5) output of the column, (6) treated final solution. 


\subsection{Analytical Methods}

\subsubsection{Lissamine Green Concentration}

Lissamine green concentration decay was followed by a Jasco V-630 Spectrophotometer (Jasco, Madrid, Spain). For it, the area under the curve from 550 to $700 \mathrm{~nm}$ was measured [32], and related to the pollutant concentration employing a calibration curve.

\subsubsection{Prednisolone Concentration}

The removal of prednisolone was followed by using the Agilent 1100-DAD detector Series HPLC (Agilent, Madrid, Spain) equipped with a C 8 column $(150 \times 4.6 \mathrm{~mm}$, i.d. $5 \mu \mathrm{m})$ ZORBAX Eclipse XDB-C8 (Agilent, Madrid, Spain), operating at room temperature. The mobile phase was water and acetonitrile and it was pumped by gradient elution for $20 \mathrm{~min}$ at $1 \mathrm{~mL} \cdot \mathrm{min}^{-1}$. Before the injection, all samples were filtered through $0.45 \mu \mathrm{m}$ PVDF filters. The column effluent was monitored spectrophotometrically at a wavelength of $246 \mathrm{~nm}$.

\subsubsection{Iron Concentration}

The concentration of ferrous iron was spectrophotometric determined according to the 1,10-phenantroline method [33] using a Spectrophotometer Jasco V-630.

\subsection{4. $\mathrm{pH}$}

The $\mathrm{pH}$ was evaluated along the treatments using a Fisher Scientific Accumet XL600 4 channel Benchtop Meters.

\subsection{Kinetic Studies}

Kinetic studies were performed to establish the model behaviour of the pollutant degradation depending on the conditions undertaken. With the software Sigma Plot version 7.101 (SPSS Inc.), the profiles of concentration of both pollutants were fitted to an adequate kinetic equation and the rate parameters were obtained. Based on the Marquard-Levenberg algorithm, this software uses an iterative method that seeks the values of the parameters to minimize the sum of the square differences between the observed and the predicted values.

\section{Results and Discussion}

\subsection{Homogeneous Experiments}

Firstly, the experiments using homogeneous catalyst were performed in the degradation of lissamine green. Due to the iron concentration is one of the most significant factors influencing the reactivity of persulfate, a series of trials was performed at different iron levels from 0 to $0.3 \mathrm{mM}$. As presented in Figure 4, different removals were observed. It can be readily found that the profile of the system with and without iron is total different. It is shown that an increase of ferrous iron concentration for the activation of $1 \mathrm{mM}$ persulfate resulted in a rise in the removal of lissamine green. These results are in accordance with previous studies that reported a similar behavior in the degradation of several pollutants such as lindane, methyl tert-butyl ether, or diuron [34-36]. Furthermore, a first stage is detected ( $5 \mathrm{~min}$ ), in which higher removals take place in all the conditions tested. Similarly, Zhu et al. [37] determined that in five minutes almost $70 \%$ of iohexol was oxidized, that can be justified with the high initial concentration of ferrous iron and persulfate that produced a rapid generation of sulfate radical [38]. 


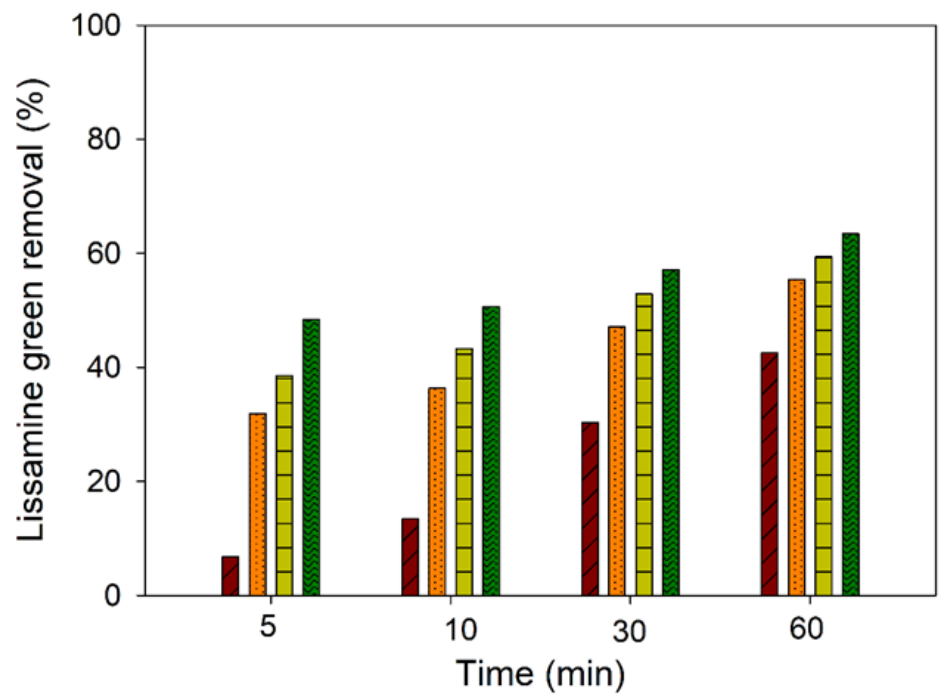

Figure 4. Effect of iron concentration on lissamine green removal: $\mathrm{Fe}^{2+}=0 \mathrm{mM}$ (diagonal lines, red), $0.1 \mathrm{mM}$ (dots, orange), $0.2 \mathrm{mM}$ (horizontal lines, lime), $0.3 \mathrm{mM}$ (zigzag lines, green). Experimental conditions: lissamine green $=7.5 \mathrm{mg} \cdot \mathrm{L}^{-1}, \mathrm{PS}=1 \mathrm{mM}$.

As it is demonstrated (Figure 4), in order to increase the pollutant removal rate, high concentrations of ferrous iron are required. However, at a level of $\mathrm{Fe}^{2+}$ higher than $0.3 \mathrm{mM}$, the iron precipitation was detected in the medium causing operational problems. In addition, when high iron concentrations are used, large amounts of iron could be detected in the effluent, which is too difficult to recovery and highly influenced by the water composition and its $\mathrm{pH}$ [16]. To overcome these problems, a possible solution is the use of heterogeneous iron catalyst that permits to keep high levels of iron provoking the rapid generation of sulfate radical from persulfate avoiding the present of iron in the final effluent. Based on this, in this study, we focused our attention in the development of a low-cost catalyst by fixation of iron on a support material. Regarding the support selection, it should be cheap, non-toxic, non-biodegradable, stable against chemicals and temperature, and have high porosity and specific surface area. The last properties are of great interest in order to allow a desired diffusion. Based on this, in this work, iron was fixed by ion exchange on a cationic resin as Amberlite IR120 $\mathrm{Na}^{+}$form.

\subsection{Lissamine Green Removal by Heterogeneous Catalysis}

Metal transition-based heterogeneous catalysts have been established as useful for persulfate and peroxymonosulfate activation. Therefore, Günay and Çimen [39] stated that iron porphyrin tetrasulfonate (FePTS) immobilized in an anion exchange resin Amberlite IRA-900 is an effective activator for peroxymonosulfate. They figured out that the supported catalyst has a positive effect on the stability of FePTS over one more cycle, but reduced the conversion of 2,4,6-trichloropenol with a slower reaction rate in comparison to the obtained results in homogeneous reaction. In this work, the use of a heterogeneous catalyst obtained by iron fixation on Amberlite IR120 $\mathrm{Na}^{+}$form was proposed, and the effect of catalyst load in the degradation process of lissamine green was evaluated and compared with the results obtained when ferrous iron was used.

At first, the morphology and chemical characterization of the catalyst were evaluated as was mentioned in materials and methods section using SEM/EDS. Following to the assembling of iron on the amberlite surface, the resin became dark brown-colored spheres, confirming that the amberlite surface had been altered. Thus, the catalyst surface exhibited a higher roughened surface as many thin particles and fine layers than raw material (Figure 5). The assessment of catalysts by EDS shows that retain relevant amounts of iron, around 30\%, with homogenous distribution (Figure 5). 

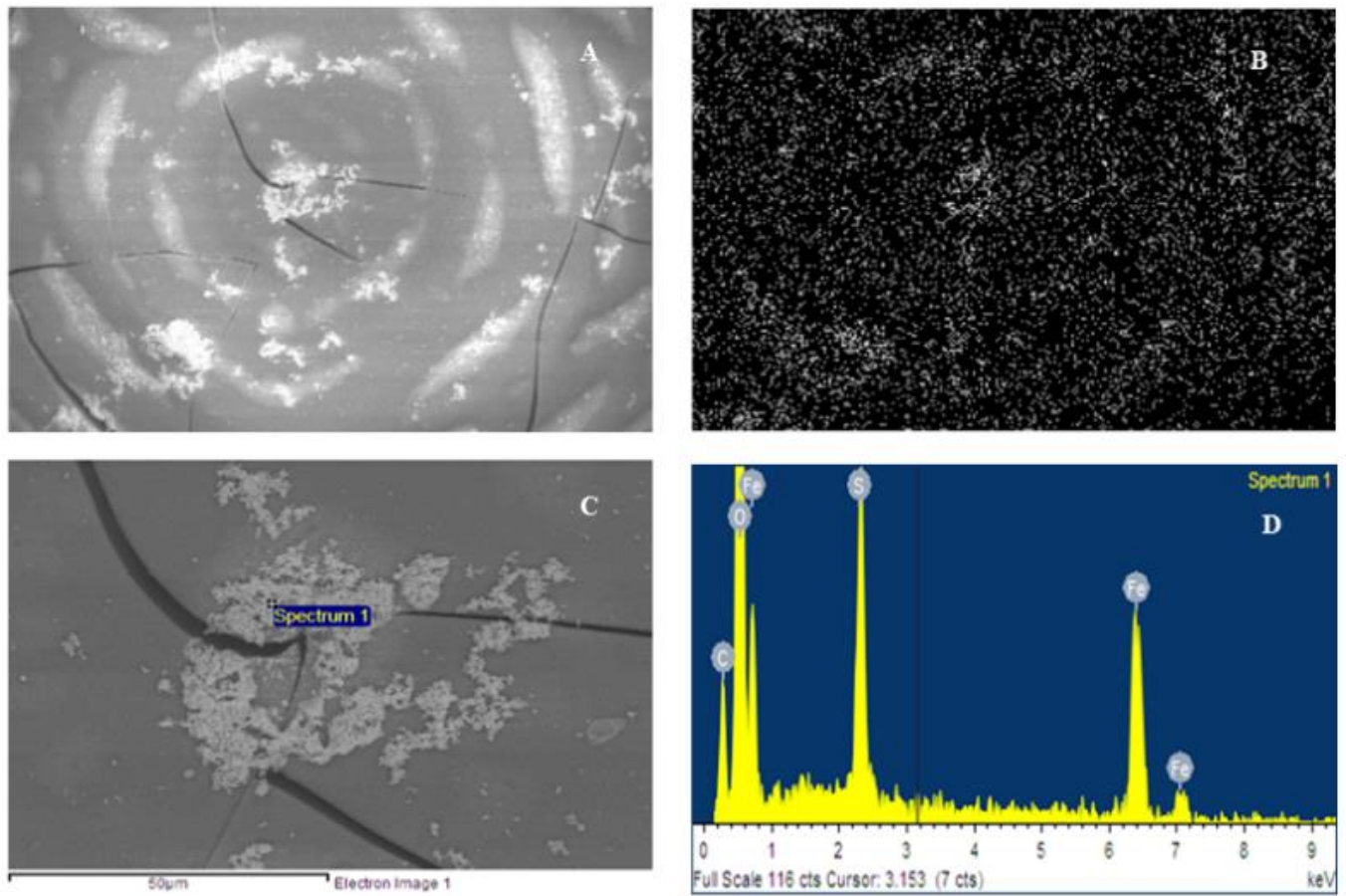

Figure 5. Scanning electron microscopy images of heterogeneous iron-based amberlite catalyst (A), mapping analysis of the iron distribution (B), electron amplified (C) and elemental mapping by Energy Dispersive Spectrometry of the region showed in image C (D).

In order to determine the influence of catalyst dosage on the lissamine green removal, several experiments were accomplished operating in batch mode at acidic conditions with a range of catalyst dosages from 5 to $30 \mathrm{~g} \cdot \mathrm{L}^{-1}\left(24-143 \mathrm{mM} \mathrm{Fe}^{2+}\right)$. As can be detected in Figure 6, the removal of lissamine green achieved in the presence of catalyst has accelerated the reaction rate meaningfully, increasing the removal levels (superior than 85\%) in shorter treatment time (lower than $30 \mathrm{~min}$ ). After experiments, slight lissamine green concentration was detected in the catalyst. Hence, these results clearly indicate that lissamine green removal was due to the oxidation of persulfate with the heterogeneous catalyst designed in this study.

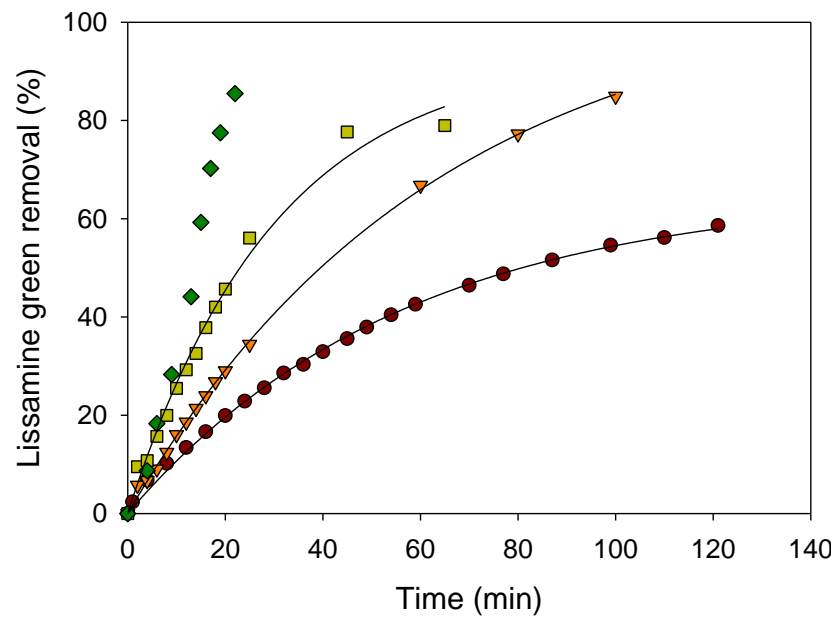

Figure 6. Effect of catalyst dosage on lissamine green removal: $0 \mathrm{~g} \cdot \mathrm{L}^{-1}(\bullet), 5 \mathrm{~g} \cdot \mathrm{L}^{-1}(\nabla), 10 \mathrm{~g} \cdot \mathrm{L}^{-1}(\square)$, $30 \mathrm{~g} \cdot \mathrm{L}^{-1}(\diamond)$. Line (-) represents the fit of the experimental data to a pseudo-first order kinetic equation. Experimental conditions: lissamine green $=7.5 \mathrm{mg} \cdot \mathrm{L}^{-1}, \mathrm{PS}=1 \mathrm{mM}$. 
The kinetics of the reaction can be assumed as a pseudo-first order, following the Equation (3):

$$
-\frac{d C}{d t}=k_{o b s} \times C
$$

where $C$ is the pollutant concentration $\left(\mathrm{mg} \cdot \mathrm{L}^{-1}\right)$ along the treatment time $(t, \mathrm{~min})$ and $k_{o b s}$ is the kinetic coefficient for the pseudo-first order reaction $\left(\mathrm{min}^{-1}\right)$. The rate constant values for the lissamine green removal are shown in the Table 1 . It is noted that the values of $k_{o b s}$ increased when the catalyst load is augmented.

Table 1. Pseudo-first order kinetics for assays testing catalyst concentration.

\begin{tabular}{ccc}
\hline Catalyst Concentration $\left(\mathbf{g} \cdot \mathbf{L}^{\mathbf{- 1}}\right)$ & $\boldsymbol{k}_{\text {obs }}\left(\mathbf{m i n}^{-\mathbf{1}}\right)$ & $\mathbf{R}^{\mathbf{2}}$ \\
\hline 0 & 0.0178 & 0.9983 \\
5 & 0.0159 & 0.9920 \\
10 & 0.0332 & 0.9897 \\
30 & 0.0928 & 0.9952 \\
\hline
\end{tabular}

To determine the maintaining catalytic activity of this iron catalyst along the time, five-cycle experiments were performed under determined optimal conditions $\left(30 \mathrm{~g} \cdot \mathrm{L}^{-1}\right.$ of catalyst). These results, showed in Figure 7, proved the great recyclability and reusability of the persulfate catalyst methodology. The final removal effectiveness in the fifth cycle was still kept at similar high level (higher than $90 \%$ in $20 \mathrm{~min}$ ). These facts were also supported by the low levels of iron that leached from the catalyst with concentrations of iron lower than $0.1 \mathrm{mg} \cdot \mathrm{L}^{-1}$ in the initial batches.

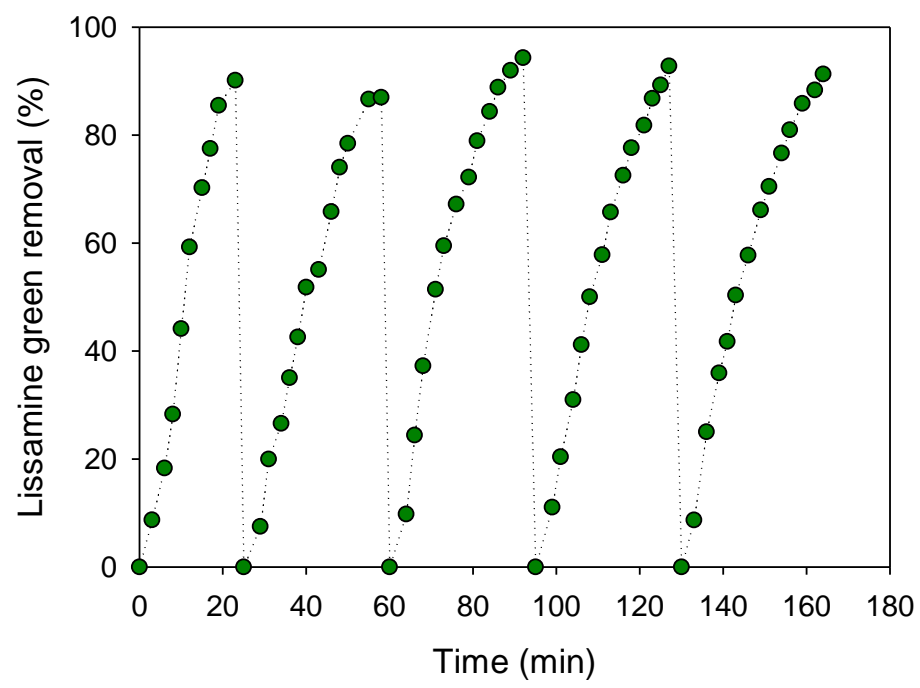

Figure 7. Reusability of catalyst in order of lissamine green removal at laboratory scale. Experimental conditions: [lissamine green $]=7.5 \mathrm{mg} \cdot \mathrm{L}^{-1},[\mathrm{PS}]=1 \mathrm{mM}$, [catalyst $]=30 \mathrm{~g} \cdot \mathrm{L}^{-1}$, volume $=0.1 \mathrm{~L}$.

One of the cornerstones of AOPs degradation processes denotes the problems faced in operating with high volumes of wastewater. Hence, the section of suitable heterogeneous catalyst strategy could be a valuable tool to avoid metal washout and to offer high catalyst activity maintaining its degradation levels. In order to elucidate the real efficiency of this process on a larger scale, three-cycle experiments were performed in a stirred tank reactor of $1.5 \mathrm{~L}$ of volume. As is shown in Figure 8, the obtained results confirm the reuse capability of this system. The lissamine green removal did not decrease from the first to the other batches. Therefore, it is notable that the reactor was able to work in batch mode treating successive volume of lissamine green in a reactor of $1.5 \mathrm{~L}$ without operational problems, keeping a high catalyst activity that allows achieving high reduction percentages in similar times. Thus, the obtained 
results confirmed that the synthetized catalyst is rough enough to be used again. Furthermore, a SEM study accomplished on the iron catalyst recovered after the last cycle showed that the mean size of the amberlite and the iron percentage were nearly the same, discarding a possible partial destruction of the amberlite due to the dual Rushton-type impeller used by the stirred tank reactor. These results confirm the adequate support selection showing an appropriate mechanical strength.

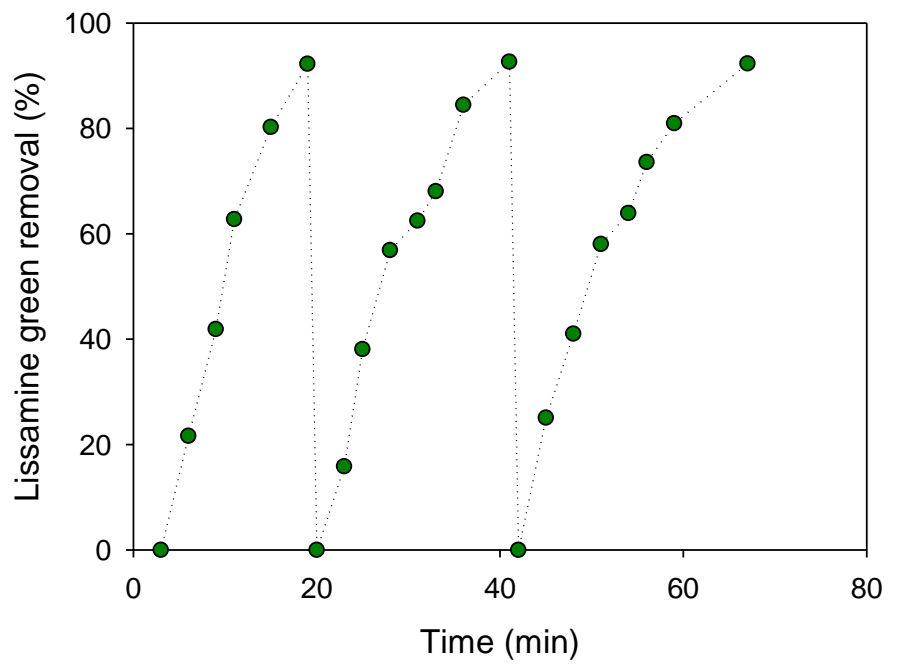

Figure 8. Reusability of catalyst in order of lissamine green removal at larger scale. Experimental conditions: [lissamine green $]=7.5 \mathrm{mg} \cdot \mathrm{L}^{-1},[\mathrm{PS}]=1 \mathrm{mM}$, [catalyst $]=30 \mathrm{~g} \cdot \mathrm{L}^{-1}$, volume $=1.5 \mathrm{~L}$.

\subsection{Continuous Treatment in a Fixed Bed Reactor}

Notwithstanding the foregoing results operating in a stirred tank reactor, the treatment of large quantities of wastewater with relatively small site requirements have significant importance. The selection of an adequate reactor is inextricably linked with the requirements and characteristics of the process and the engineering aspects. When working in continuous mode, abrasion of the catalyst and production of very fine particles may occur at elevated treatment times, which requires the separation of the catalyst. This represents high costs and further operational time. For this reason, the operation at a bench-scale fixed bed reactor was then approached.

Based on the good results obtained in the lissamine green removal, more studies were performed using as a pollutant other pharmaceutical compound found in wastewater at higher levels as prednisolone. Firstly, the effect of the initial persulfate concentration was evaluated operating at catalyst load of $30 \mathrm{~g} \cdot \mathrm{L}^{-1}$ for both pollutants. As an example, the prednisolone removal is shown in Figure 9. It can be said that the contaminant removal was greatly accelerated with the increasing oxidant concentrations ranging from 0.1 to $1 \mathrm{mM}$, which was due to the increasing generation of sulfate radicals. This behavior is in accordance with previous studies that reported the relationship between the increase of oxidant concentration and the persulfate concentration [40]. 


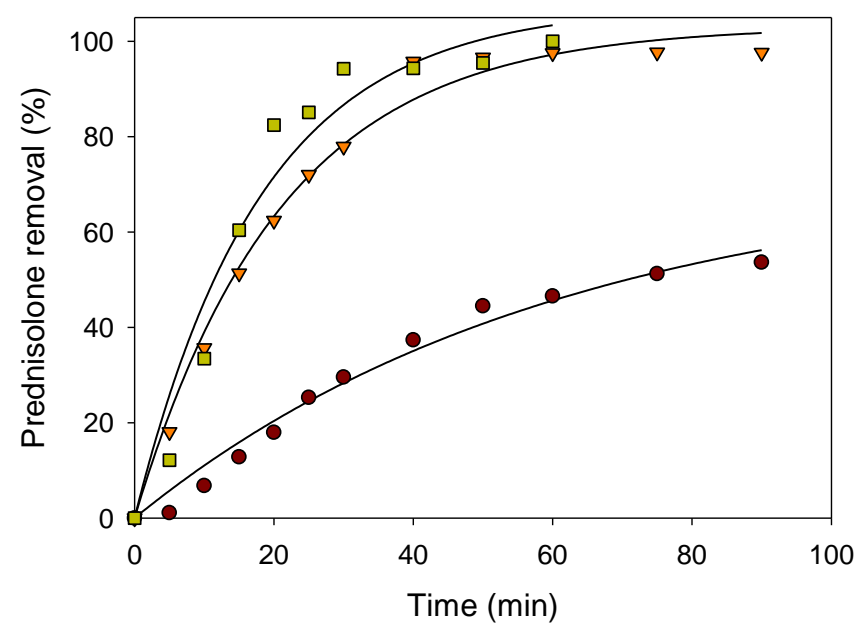

Figure 9. Effect of PS concentration on the removal of prednisolone: $0.1 \mathrm{mM}(\bullet), 0.5 \mathrm{mM}(\nabla), 1 \mathrm{mM}(\square)$. Line (-) represents the fit of the experimental data to pseudo-first order kinetic equation. Experimental conditions: [prednisolone] $=25 \mathrm{mg} \cdot \mathrm{L}^{-1}$, [catalyst $]=30 \mathrm{~g} \cdot \mathrm{L}^{-1}$.

Hereafter, the experiments with the fixed bed reactor were carried out with both pollutants. This reactor was filled with glass beads (diameter of $7 \mathrm{~mm}$ ) and $3 \mathrm{~g}$ of catalyst with the aim of approaching to an ideal plug flow model and good liquid distribution along the fixed bed. At this scale, the importance of the inlet flow rate must be stressed, as the residence time should be much higher than the removal rate recorded at flask scale. To determine the influence of the reaction time on the activity and stability of the catalytic action of the iron amberlite, the removal of prednisolone and lissamine green was carried out in a flow-system working at different solution flux. In all cases, each steady state was maintained for at least 3 times the residence time.

Considering a hydrodynamic behavior of plug flow model along a fixed reactor and a pseudo-first order kinetic (with kinetic constants of $0.0549 \mathrm{~min}^{-1}$ and $0.0928 \mathrm{~min}^{-1}$ for prednisolone and lissamine green, respectively) an exponential model that relates the pollutant concentration in the outlet effluent and residence time was considered (Equation (4)).

$$
C=C_{0} \times e^{-k_{o b s} \tau}
$$

where $C_{0}$ is the pollutant concentration at initial time $\left(25 \mathrm{mg} \cdot \mathrm{L}^{-1}\right.$ and $7.5 \mathrm{mg} \cdot \mathrm{L}^{-1}$ for prednisolone and lissamine green, respectively), $k_{o b s}$ is the pseudo-first order kinetic, and $\tau$ is the residence time (min).

To confirm the model for its application in a flow-system, the comparison between the experimental data and the obtained values from model have been carried out in Table 2. In all cases, the deviation between experimental data and theoretical data considering ideal behavior is clear. These results indicated that the hydrodynamic behavior of flow along a fixed reactor cannot be assumed as ideal plug flow model behavior. Notwithstanding, in both cases the removal degree increases with the residence time raised. Thus, removal levels of approximately $95 \%$ and $90 \%$ were achieved for prednisolone and lissamine green, respectively when the system operated at residence time of $60 \mathrm{~min}$.

Table 2. Experimental and theoretical levels of lissamine green and prednisolone removal at different residence times.

\begin{tabular}{ccccc}
\hline$\tau(\min )$ & $\begin{array}{c}C / C_{0} \text { Lissamine Green } \\
\text { (Experimental) }\end{array}$ & $\begin{array}{c}C / C_{\mathbf{0}} \text { Lissamine Green } \\
\text { (Data from Equation (4)) }\end{array}$ & $\begin{array}{c}C / C_{\mathbf{0}} \text { Prednisolone } \\
\text { (Experimental) }\end{array}$ & $\begin{array}{c}C / C_{\mathbf{0}} \text { Prednisolone (Data } \\
\text { from Equation (4)) }\end{array}$ \\
\hline 10 & 0.553 & 0.3953 & 0.486 & 0.5775 \\
20 & 0.353 & 0.1563 & 0.336 & 0.3335 \\
40 & 0.197 & 0.0244 & 0.049 & 0.1112 \\
60 & 0.102 & 0.0038 & 0.043 & 0.0371 \\
\hline
\end{tabular}


After the flow-system experiments, the iron catalyst was evaluated using SEM images in order to determine the changes suffered on the surface that can affect the morphology of the particles. Similarly, to the previous experiments, the catalyst is rather robust without any operational problems, being able to treat high volume of wastewater using a small reactor.

\section{Conclusions}

In this work, the removal of two pharmaceuticals compounds (lissamine green and prednisolone) through sulfate radicals-based technology was assessed. Thus, the production of sulfate radicals was accomplished by activating the oxidant persulfate with iron. In order to evaluate the effectiveness of the process, homogeneous and heterogeneous catalysis were carried out and the essential parameters, such as iron concentration and persulfate dosage, were evaluated. Experimental trials of both pollutants at lab scale achieved $85 \%$ of degradation within 25 min with $30 \mathrm{~g} \cdot \mathrm{L}^{-1}$ of catalyst and persulfate $1 \mathrm{mM}$. Moreover, the reuse capability of the catalyst was performed with the optimal conditions. To this effect, several cycles were carried out at lab scale and in a reactor of $1.5 \mathrm{~L}$. Based on the results, it can be said that the catalyst is rough enough to be used in this system. Besides that, the operation at a bench-scale in a fixed bed reactor was accomplished. Different residence times were evaluated and it was demonstrated that this continuous treatment is feasible from an enginering and enviromental point of view.

Author Contributions: Conceptualization, M.P. and M.A.S.; methodology, M.P. and A.S.; validation, M.P. and A.S.; formal analysis, M.A.S. and M.A.; investigation, M.A.; resources, M.P. and M.A.S.; data curation, M.A.; writing—original draft preparation, M.A., M.P. and M.A.S; writing—review and editing, M.A.S.; visualization, M.A., M.P. and M.A.S.; supervision, M.P. and M.A.S.; project administration, M.P. and M.A.S.; funding acquisition, M.A.S.

Funding: This research has been financially supported by the Spanish Ministry of Economy and Competitiveness (MINECO) (Project CTM2017-87326-R).

Acknowledgments: María Arellano is grateful to Xunta de Galicia and European Social Fund (ESF) for her PhD grant.

Conflicts of Interest: The authors declare no conflict of interest.

\section{References}

1. Begley, C.; Caffery, B.; Chalmers, R.; Situ, P.; Simpson, T.; Nelson, J.D. Review and analysis of grading scales for ocular surface staining. Ocul. Surf. 2019, 17, 208-220. [CrossRef]

2. Ćurković, L.; Ljubas, D.; Šegota, S.; Bačić, I. Photocatalytic degradation of Lissamine Green B dye by using nanostructured sol-gel $\mathrm{TiO}_{2}$ films. J. Alloys Compd. 2014, 604, 309-316. [CrossRef]

3. Alfaya, E.; Iglesias, O.; Pazos, M.; Sanromán, M.A. Environmental application of an industrial waste as catalyst for the electro-Fenton-like treatment of organic pollutants. RSC Adv. 2015, 5, 14416-14424. [CrossRef]

4. Alim, S.A.; Rao, T.S.; Raju, I.M.; Kumar, M.R.; Lakshmi, K.V.D. Fabrication of visible light driven nano structured Copper, Boron codoped $\mathrm{TiO}_{2}$ for photocatalytic removal of Lissamine Green B. J. Saudi Chem. Soc. 2019, 23, 92-103. [CrossRef]

5. Kongsted, P.; Svane, I.M.; Lindberg, H.; Daugaard, G.; Sengeløv, L. Low-dose prednisolone in first-line docetaxel for patients with metastatic castration-resistant prostate cancer: Is there a clinical benefit? Urol. Oncol. Semin. Orig. Investig. 2015, 33, 494.e15-494.e20. [CrossRef]

6. Bal, N.; Kumar, A.; Nugegoda, D. Assessing multigenerational effects of prednisolone to the freshwater snail, Physa acuta (Gastropoda: Physidae). J. Hazard. Mater. 2017, 339, 281-291. [CrossRef]

7. Yin, K.; He, Q.; Liu, C.; Deng, Y.; Wei, Y.; Chen, S.; Liu, T.; Luo, S. Prednisolone degradation by UV/chlorine process: Influence factors, transformation products and mechanism. Chemosphere 2018, 212, 56-66. [CrossRef]

8. De Vrieze, E.; Van Kessel, M.A.H.J.; Peters, H.M.; Spanings, F.A.T.; Flik, G.; Metz, J.R. Prednisolone induces osteoporosis-like phenotype in regenerating zebrafish scales. Osteoporos Int. 2014, 25, 567-578. [CrossRef]

9. Bal, N.; Kumar, A.; Du, J.; Nugegoda, D. Prednisolone impairs embryonic and posthatching development and shell formation of the freshwater snail, Physa acuta. Environ. Toxicol. Chem. 2016, 35, 2339-2348. [CrossRef] 
10. Bertagna Silva, D.; Cruz-Alcalde, A.; Sans, C.; Giménez, J.; Esplugas, S. Performance and kinetic modelling of photolytic and photocatalytic ozonation for enhanced micropollutants removal in municipal wastewaters. Appl. Catal. B Environ. 2019, 249, 211-217. [CrossRef]

11. Sopaj, F.; Rodrigo, M.A.; Oturan, N.; Podvorica, F.I.; Pinson, J.; Oturan, M.A. Influence of the anode materials on the electrochemical oxidation efficiency. Application to oxidative degradation of the pharmaceutical amoxicillin. Chem. Eng. J. 2015, 262, 286-294. [CrossRef]

12. Poza-Nogueiras, V.; Rosales, E.; Pazos, M.; Sanromán, M.Á. Current advances and trends in electro-Fenton process using heterogeneous catalysts-A review. Chemosphere 2018, 201, 399-416. [CrossRef]

13. Muñoz-Morales, M.; Sáez, C.; Cañizares, P.; Rodrigo, M.A. A new electrochemically-based process for the removal of perchloroethylene from gaseous effluents. Chem. Eng. J. 2019, 361, 609-614. [CrossRef]

14. Barba, S.; Villaseñor, J.; Cañizares, P.; Rodrigo, M.A. Strategies for the electrobioremediation of oxyfluorfen polluted soils. Electrochim. Acta 2019, 297, 137-144. [CrossRef]

15. Brillas, E.; Martínez-Huitle, C.A. Decontamination of wastewaters containing synthetic organic dyes by electrochemical methods. An updated review. Appl. Catal. B Environ. 2015, 166-167, 603-643. [CrossRef]

16. Wang, J.; Wang, S. Activation of persulfate (PS) and peroxymonosulfate (PMS) and application for the degradation of emerging contaminants. Chem. Eng. J. 2017, 334, 1502-1517. [CrossRef]

17. Ike, I.A.; Linden, K.G.; Orbell, J.D.; Duke, M. Critical review of the science and sustainability of persulphate advanced oxidation processes. Chem. Eng. J. 2018, 338, 651-669. [CrossRef]

18. Feng, Y.; Wu, D.; Deng, Y.; Zhang, T.; Shih, K. Sulfate radical-mediated degradation of sulfadiazine by $\mathrm{CuFeO}_{2}$ rhombohedral crystal-catalyzed peroxymonosulfate: Synergistic effects and mechanisms. Environ. Sci. Technol. 2016, 50, 3119-3127. [CrossRef]

19. Ghanbari, F.; Moradi, M. Application of peroxymonosulfate and its activation methods for degradation of environmental organic pollutants: Review. Chem. Eng. J. 2017, 310, 41-62. [CrossRef]

20. Guerra-Rodríguez, S.; Rodríguez, E.; Singh, D.N.; Rodríguez-Chueca, J. Assessment of sulfate radical-based advanced oxidation processes for water and wastewater treatment: A review. Water 2018, 10, 1828. [CrossRef]

21. Gao, Y.; Zhang, Z.; Li, S.; Liu, J.; Yao, L.; Li, Y.; Zhang, H. Insights into the mechanism of heterogeneous activation of persulfate with a clay/iron-based catalyst under visible LED light irradiation. Appl. Catal. B Environ. 2016, 185, 22-30. [CrossRef]

22. Pulicharla, R.; Drouinaud, R.; Brar, S.K.; Drogui, P.; Proulx, F.; Verma, M.; Surampalli, R.Y. Activation of persulfate by homogeneous and heterogeneous iron catalyst to degrade chlortetracycline in aqueous solution. Chemosphere 2018, 207, 543-551. [CrossRef] [PubMed]

23. Zhang, P.; Tan, X.; Liu, S.; Liu, Y.; Zeng, G.; Ye, S.; Yin, Z.; Hu, X.; Liu, N. Catalytic degradation of estrogen by persulfate activated with iron-doped graphitic biochar: Process variables effects and matrix effects. Chem. Eng. J. 2019, 378, 122141. [CrossRef]

24. Arellano, M.; Sanromán, M.A.; Pazos, M. Electro-assisted activation of peroxymonosulfate by iron-based minerals for the degradation of 1-butyl-1-methylpyrrolidinium chloride. Sep. Purif. Technol. 2019, 208, 34-41. [CrossRef]

25. Oh, W.-D.; Dong, Z.; Lim, T.-T. Generation of sulfate radical through heterogeneous catalysis for organic contaminants removal: Current development, challenges and prospects. Appl. Catal. B Environ. 2016, 194, 169-201. [CrossRef]

26. Zhao, Q.; Mao, Q.; Zhou, Y.; Wei, J.; Liu, X.; Yang, J.; Luo, L.; Zhang, J.; Chen, H.; Chen, H.; et al. Metal-free carbon materials-catalyzed sulfate radical-based advanced oxidation processes: A review on heterogeneous catalysts and applications. Chemosphere 2017, 189, 224-238. [CrossRef] [PubMed]

27. Tang, L.; Liu, Y.; Wang, J.; Zeng, G.; Deng, Y.; Dong, H.; Feng, H.; Wang, J.; Peng, B. Enhanced activation process of persulfate by mesoporous carbon for degradation of aqueous organic pollutants: Electron transfer mechanism. Appl. Catal. B Environ. 2018, 231,1-10. [CrossRef]

28. Iglesias, O.; Rosales, E.; Pazos, M.; Sanromán, M.A. Electro-Fenton decolourisation of dyes in an airlift continuous reactor using iron alginate beads. Environ. Sci. Pollut. Res. 2013, 20, 2252-2261. [CrossRef] [PubMed]

29. Díez, A.M.; Ribeiro, A.S.; Sanromán, M.A.; Pazos, M. Optimization of photo-Fenton process for the treatment of prednisolone. Environ. Sci. Pollut. Res. 2018, 25, 27768-27782. [CrossRef]

30. Rosales, E.; Iglesias, O.; Pazos, M.; Sanromán, M.A. Decolourisation of dyes under electro-Fenton process using Fe alginate gel beads. J. Hazard. Mater. 2012, 213-214, 369-377. [CrossRef] 
31. Rosales, E.; Pazos, M.; Longo, M.A.; Sanromán, M.A. Electro-Fenton decoloration of dyes in a continuous reactor: A promising technology in colored wastewater treatment. Chem. Eng. J. 2009, 155, 62-67. [CrossRef]

32. Green, F.J. The Sigma-Aldrich Handbook of Stains, Dyes and Indicators; Aldrich Chemical Cop.: Milwaukee, WI, USA, 1990.

33. Tamura, H.; Goto, K.; Yotsuyanagi, T.; Nagayama, M. Spectrophotometric determination of iron (II) with 1,10-phenanthroline in the presence of large amounts of iron (III). Talanta 1974, 21, 314-318. [CrossRef]

34. Cao, J.; Zhang, W.-X.; Brown, D.G.; Sethi, D. Oxidation of lindane with Fe(II)-activated sodium persulfate. Environ. Eng. Sci. 2008, 25, 221-228. [CrossRef]

35. Chen, K.F.; Kao, C.M.; Wu, L.C.; Liang, S.H.; Surampalli, R.Y. Methyl Tert-Butyl Ether (MTBE) degradation by ferrous ion-activated persulfate oxidation: Feasibility and kinetics studies. Water Environ. Res. 2009, 81, 687-694. [CrossRef] [PubMed]

36. Romero, A.; Santos, A.; Vicente, F.; González, C. Diuron abatement using activated persulphate: Effect of $\mathrm{pH}$, Fe(II) and oxidant dosage. Chem. Eng. J. 2010, 162, 257-265. [CrossRef]

37. Zhu, J.-P.; Lin, Y.-L.; Zhang, T.-Y.; Cao, T.-C.; Xu, B.; Pan, Y.; Zhang, X.-T.; Gao, N.-Y. Modelling of iohexol degradation in a Fe(II)-activated persulfate system. Chem. Eng. J. 2019, 367, 86-93. [CrossRef]

38. Bu, L.; Shi, Z.; Zhou, S. Modeling of Fe(II)-activated persulfate oxidation using atrazine as a target contaminant. Sep. Purif. Technol. 2016, 169, 59-65. [CrossRef]

39. Günay, T.; Çimen, Y. Degradation of 2,4,6-trichlorophenol with peroxymonosulfate catalyzed by soluble and supported iron porphyrins. Environ. Pollut. 2017, 231, 1013-1020. [CrossRef]

40. Luo, C.; Jiang, J.; Ma, J.; Pang, S.; Liu, Y.; Song, Y.; Guan, C.; Li, J.; Jin, Y.; Wu, D. Oxidation of the odorous compound 2,4,6-trichloroanisole by UV activated persulfate: Kinetics, products, and pathways. Water Res. 2016, 96, 12-21. [CrossRef]

(C) 2019 by the authors. Licensee MDPI, Basel, Switzerland. This article is an open access article distributed under the terms and conditions of the Creative Commons Attribution (CC BY) license (http://creativecommons.org/licenses/by/4.0/). 